\title{
Role of Short Tandem Repeat DNA in Forensic Casework in the UK-Past, Present, and Future Perspectives
}

BioTechniques 32:366-385 (February 2002)

\section{Peter Gill \\ Forensic Science Service, Birmingham, UK}

\section{DEVELOPMENT OF \\ MULTIPLEXED SYSTEMS}

Early multiplexes consisted of few loci that were based on simple short tandem repeats (STRs). The four-locus "quadruplex" was probably the first to be widely used (44); because it consisted of few STRs, the match probability was consequently high -1 in 10000 . In 1996, a six-locus STR system $(57,58)$ combined with the amelogenin sex test (61) was introduced-known as the "second generation multiplex" (SGM). Because this system utilized complex STRs D21S11 and HUMFIBRA/FGA (47), which have greater variability than simple STRs, the match probability was consequently decreased to 1:50 million. In the UK, the introduction of SGM coincided with the implementation of the UK National DNA Database (75). More than a million samples are now stored on the database. As databases become much larger (numbering several millions), it is necessary to ensure that the match probability of the system is sufficient to minimize the chance of two unrelated individuals matching accidentally. Consequently, a new system known as the AmpFl STR ${ }^{\circledR}$ SGM Plus ${ }^{\mathrm{TM}}$ (Applied Biosystems, Foster City, CA, USA) (18) was introduced in 1999 and comprised 10 STR loci and amelogenin, replacing the previous SGM system. The probability of a match between two unrelated people is approximately $10^{-13}$. For a full DNA profile, our practice is to report a default match probability of less than 1 in 1 billion. This figure is conservative relative to sampling error and $\mathrm{F}_{\text {st }}$ corrections (25). To ensure the continuity of the DNA database so that the new system could be used to match samples that had been collated in previ- ous years, all six loci of the older SGM system were retained in the new Amp Fl STR SGM Plus system.

\section{Development and Harmonization of National DNA Databases}

The harmonization of STR loci has been achieved by collaboration at the international level. Notably, the European DNA profiling group (EDNAP) carried out a series of successful studies to identify and recommend STR loci for the forensic community to use. This work began with an evaluation of the simple STRs, HUMTH01 and HUMVWFA (43). Subsequently, the group evaluated D21S11 and HUMFIBRA/FGA (31). Recommendations on the use of STRs have been published by the International Society of Forensic Genetics $(7,51)$.

To date, several European countries have legislated to implement national DNA databases that are based on STRs. In Europe, there has been a drive to standardize loci across countries to meet the challenge of increasing crossborder crime. In particular, a European Community (EC)-funded initiative led by the European Network of Forensic Science Institutes (ENFSI) was responsible for coordinating collaborative exercises to validate commercially available multiplexes for general use within the EC (34). National DNA databases were introduced in 1997 in Holland and Austria, 1998 in Germany, and 1999 in Finland and Norway. Furthermore, databases are currently planned for Belgium, Sweden, Denmark, Switzerland, and Spain. A parallel process is occurring in Canada $(28,67)$ and the US (42) where standardization is based on 13 combined DNA index system (CODIS) loci (Table 1). 
Based on the initial EDNAP exercises and on recommendations by ENSFI and the Interpol working party (46), four systems were defined as the European standard set of loci-HUMTH01, HUMVWFA31, D21S11, and HUMFIBRA/FGA. Recently, three additional loci were added to this set-D3S1358, D8S1179, and D18S51. These loci are included in the multiplexed commercial systems of Applied Biosystems and Promega (Madison, WI, USA) (Table 1).

A great advantage of STRs is that they are reliably easy to identify and collate, regardless of the analysis platform that is used. Typically, in European laboratories, flatbed automated fluorescent sequencers are utilized, whereas in North America, singlechannel capillary gel electrophoresis (CE) instruments are predominantly used. For high-throughput laboratories, interest is growing in the utilization of multichannel CE instruments.

\section{The UK National DNA Database}

The UK National DNA Database (75) is projected to reach a target 5 million samples within a few years. The system operates by the analysis of buccal (mouth) scrapes or hair roots taken from any individual suspected or convicted of a recordable offense. These are known as criminal justice samples. The results are stored on computer in the form of a digital code that is based on the nomenclature of each STR. This type of database is known as an intelligence database. During normal casework, operational laboratories carry out the analysis of crime material such as semen or bloodstains. The DNA profiles derived from these samples are compared against the criminal justice samples in the existing database. If a match is found, then police are informed to enable further investigations. Although DNA profiling was primarily used to solve serious crimes, the majority of matches currently originate from petty offenses such as burglary, although these may result in matches to more serious offenses.

\section{Population Databases}

Population databases are distinct from intelligence databases. The for- mer are used to calculate the rarity of a profile in a population to give an indication to the court of the strength of the DNA evidence. Because allele frequencies are different between racial groups, it is the usual practice to collect databases from the major racial groups that comprise the most common population groups of a country. Populations are composed of subpopulations that may be distinct as a consequence of the nonrandom mating that results in incomplete mixing. Consequently, the greatest differences are found between racial groups such as White Caucasian and African, and relatively minor differences are found between groups that are the same race but live in different locations. The question is whether the database that is utilized is representative, given that most databases used for forensic purposes are based on broad, random collections of racial groups that do not necessarily take into account subpopulation structure. For example, there are three different databases that are used in the UK-namely, White Caucasian, Afro-Caribbean, and Asian (Indian subcontinent). The Asian database comprises people whose ancestors originated from a wide geographical and cultural background.

The National Research Council (NRC) report (50) took the view that the subgroup to which the suspect belongs is irrelevant, since it is the probability of the evidence if the suspect is innocent and the crime was committed by a random individual. Foreman et al. (26) pointed out that it is the ethnicity of the offender that is relevant and not the ethnicity of the defendant. However, if the court wishes to evaluate the scenario in which it is claimed that the subpopulation of the offender is the same as that of the suspect (e.g., if all potential suspects are from a particular locality or group of people), the question arises of whether the database is representative.

To answer this question, fairly extensive studies have been carried out to measure the genetic differences between different groups of people $(4,10$, $25,26,30,73)$. These studies support the notions that differences between subpopulations are low and discernable differences are unlikely within cosmopolitan populations. However, the theoretical variation between subpopulations can be accommodated by the use of a correction factor $\left(\mathrm{F}_{\mathrm{ST}}\right)$ (5). Differences between subpopulations are minor, and $\mathrm{F}_{\mathrm{ST}}$ is less than $1 \%$ (unless the population is highly inbred). This means that inferences derived about the frequencies of alleles in a specific subpopulation for which a database is not available can be accom modated by using a general database as long as $\mathrm{F}_{\mathrm{ST}}$ is considered.

\section{Assessing the Strength of the Evidence from a Match Derived from the Intelligence Database}

The strength of the DNA evidence resulting from an intelligence database match is always presented as a frequency or likelihood ratio (LR) calculated from a relevant population database. The question of whether searching an intelligence database for a match affected the strength of the evidence was addressed by the NRC report (50). They recommended that an adjustment be applied by multiplying the match probability $\left(P m_{i}\right)$ for the ith genotype by the number of people on the database, resulting in an adjusted estimate $(P \mathrm{~m})$. Using an example of an intelligence database of $N=1000$ and a multiplex with $P m_{i}$ of $10^{-6}$, this would result in a $P m$ of 0.001 . Balding and Donnelly (3) have criticized the above approach on the grounds that the weight of the evidence for a DNA database search can be expressed as $P m_{i}$, which is the match probability unadjusted for the number of people in the database. However, they advise the use of a very low prior probability unless there is any other non-DNA evidence to implicate the suspect.

Stockmar (59) reevaluated the NRC recommendation by defining the formulation of two alternative hypotheses that compared the probability of the evidence if the source of the DNA profile is in the DNA database $\left(p E \mid H_{i n}\right)$, compared to the probability of the evidence if the source of the DNA profile is not in the DNA database $\left(p E \mid H_{n o t \_i n}\right)$ :

$$
L R=\frac{p\left(\text { Profile } \mid H_{\text {in }}\right)}{p\left(\text { Profile } \mid H_{\text {not_in }}\right)}=\frac{1}{N P m_{i}}
$$


Table 1. A Comparison of Different Commercial STR Multiplexes

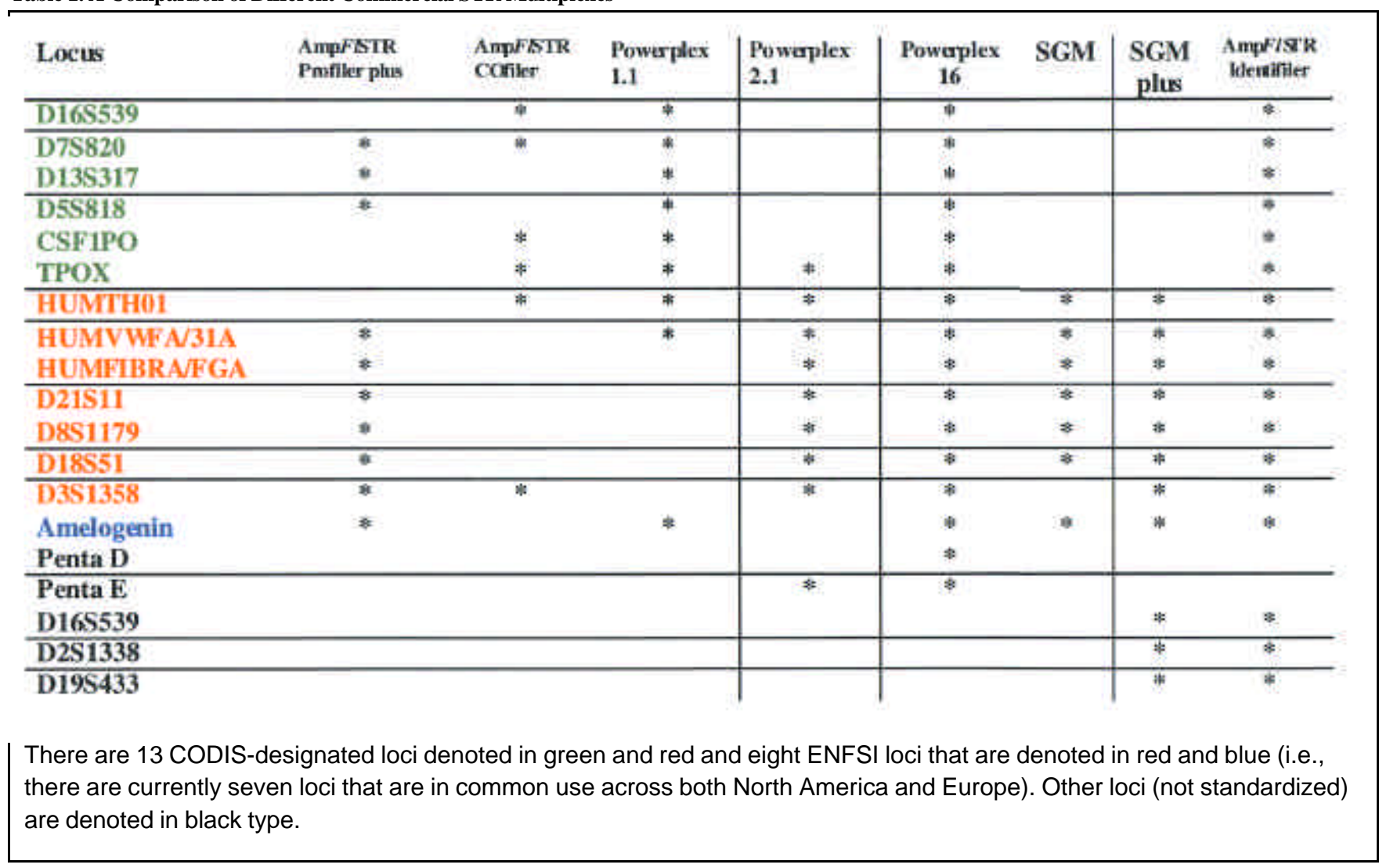

Whereas the DNA Advisory Board (19) accepted both methods to be legitimate, they continued to support the NRCII recommendations on the grounds that Bayesian logic (i.e., the use of prior odds) was not required for its formulation.

At a very practical level, the same calculation can be used to determine the chance of an adventitious match on the DNA database. This is defined as a match between a crime-stain profile and an innocent individual whose profile is derived from a criminal justice sample. Consequently, the larger the intelligence database becomes, the greater the chance of an adventitious match. Alternatively, the greater the match probability is of the DNA profiling system used, the greater the chance of an adventitious match.

Suppose that there are 1 million samples in an intelligence database. If a multiplex system is used that has a match probability $\left(P m_{i}\right)$ of $5 \times 10^{-8}$ (as for the SGM), then $P m_{i} \times N=0.02$ and this means that approximately 1 in 50 samples (for which the true match is not in the database) that are compared to this intelligence database will match by chance. Clearly, much lower match probabilities are needed to accommodate large intelligence databases. It is projected that databases of several million will exist within the next few years. Therefore, the question arises of how low the match probability should be.

As the database grows, it is implicit that the match probability needs to be reduced to keep the potential number of adventitious matches to a minimum. To fulfill this requirement, the SGM system was upgraded in 1999 in the UK. The six original loci were supplemented by four additional loci to produce the AmpFlSTR SGM Plus system (Table 1). Consequently, a much lower random match probability was achieved $\left(10^{-13}\right)(25)$. Now the chance of an adventitious match against a database size of 1 million is just $10^{-7}$ or 1 in 10 million samples. If a database reaches a size of 5 million, then the chance of an adventitious match (for full DNA profiles and unrelated individuals) is 1 in 2 million samples.
To put this in perspective, the only relevant comparisons are between criminal justice samples and crime samples (rather than comparisons within the database itself). Whereas approximately 1 million DNA profiles are currently retained on the database, to date, they have been compared against approximately 100000 samples taken from crime scenes. This means that the ratio of crime-stain profiles to criminal justice profiles is approximately $1: 10$. Consequently, adventitious matches between crime-stain profiles and criminal justice profiles are much less likely to occur than in comparisons between criminal justice samples only. Given the target size of the intelligence DNA database and the lower number of comparisons with crime samples, the match probability of the AmpFlSTR SGM Plus system should suffice for the foreseeable future.

Additional loci further decrease the match probabilities. This may be im portant for countries where the population is much larger than that of the UK and the consequent target size of the database may be larger. The Promega 
16-plex (Powerplex ${ }^{\circledR} 16$ BIO System) and the Applied Biosystems 16-plex (AmpFlSTR Identifiler ${ }^{\mathrm{TM}}$ ) systems have match probabilities in the region of 10-17. Only 1 in $10^{11}$ individuals will match an individual in a database of 1 million, increasing to 1 in $5 \times 10^{10}$ in a database size of 50 million individuals. However, it must be noted that these calculations ignore two important effects: (i) close relatives (especially brothers) will have a greater probability of matching each other, and (ii) partial DNA profiles will have much higher match probabilities.

The reason that National DNA databases are called intelligence databases arises from the fact that DNA profiles that match suspects do not provide direct proof of guilt or innocence. The strength of the DNA evidence measured as an LR or match probability of a DNA profile is unaffected by potential adventitious matches. However, before going to court, the investigating officers will build the case based on all of the available evidence (e.g., footwear prints, fibers, eyewitness statements, and the presence of the victim's blood on a suspect's clothing).

In cases where there is little nonDNA evidence or the non-DNA evidence suggests that the defendant is innocent, the overall combined strength of the evidence against the suspect is decreased. This can be demonstrated mathematically (21). However, juries currently assess all of the evidence in a case using an intuitive approach to decide the guilt or innocence.

\section{Uniqueness}

Whereas the preceding discussion assesses the chance that a DNA profile will match someone in a hypothetical DNA database, an assessment of whether a DNA profile is unique in an unsampled population requires different considerations. Balding (2) takes the position that something is either unique or it is not-it is not possible to assess objectively unless the entire relevant population has been sampled. Therefore, it is necessary to estimate a probability that is based on the information from the DNA frequency database and population genetics theory. To do this, Balding (2) assesses the ques- tion, "Given that we know there is one person with this profile, what is the probability that there are other people of the same type?" To calculate this probability, he takes account of familial relationships within the population, since a suspect is more likely to share the same DNA profile as his brother than a randomly chosen member of the population of size $N+1$. Accordingly, Balding (2) utilizes the following definition, where $U$ is the event that the DNA profile of $S$, the defendant, matches the crime scene profile and there is no matching individual in a population of unprofiled individuals where $p$ is the random match probability. $U$ is evaluated against all of the evidence $(E)$ presented in the case.

$$
P(U \mid E)=\frac{(1-p)^{N}}{1+N p}
$$

Using an arbitrary $P(L E)>99.9 \%$, Balding (2) shows that the $99.9 \%$ criterion for uniqueness is nearly always achieved when more than 11 STR loci are used and the population size is $10^{7}$. The assumption is made that the defendant is as likely to have left the crime stain as any member of some specified population. Interestingly, the more STRs are used, the less the contribution to the calculation from unrelated individuals - the calculation is dominated by brothers and, consequently, much larger populations ( 1 billion) can be accommodated by just 12 loci.

In fact, the Balding calculation is, in both practical and philosophical terms, very similar to that of Budowle et al. (9), who also consider the conditions where a multiple locus DNA profile may be considered to be unique within the context of a case (source attribution). It is emphasized that an assessment within the context of a world population is not particularly relevant since the pool of potential suspects must always be limited. Budowle et al. (9) use the binomial formula:

$$
\left(1-p_{x}\right)^{N}
$$

This is the same as the numerator of the Balding (2) formula. When both $N$ and $p$ are small, then the denominator, $1+N p \approx 1$. With either formula, using an estimate of $N=260$ million (approximately the size of the US population), a random match probability of less than $3.9 \times 10^{-11}$ will confer at least $99 \%$ confidence that the evidentiary profile is "unique" in the population, under the assumption that relatives are excluded from the pool.

Whereas Balding (2) recommends the calculation of both related and unrelated individuals in the population, $\mathrm{Bu}-$ dowle et al. (9) take the stance of always considering the relatives in a separate calculation only if relevant to the case. It may be considered that relatives could not have had access to the crime scene. If the case scenario requires a consideration of relatives, then, clearly, the population of suspects must be very much smaller than for a general population. Chakraborty et al. (12) report that the most common conditional probability for a 13-locus STR DNA profile is expected to occur in no more than 1 in 40000 among full siblings.

The greatest difference between the Balding approach and that of Budowle et al. seem to rest on a philosophical issue. Balding asserts that source attribution is impossible if there is substantial non-DNA evidence that supports the innocence of the defendant. Conversely, the DNA Advisory Board (19) stated, "If the DNA evidence appears to have come from the defendant, then the only reasonable explanation is that it did come from the defendant and other explanations of the data should be examined". In particular, the relevance of the evidence may be an issue-it is possible that there are innocent reasons for the transfer of a DNA profile (this is an especially important consideration relating to low copy number DNA profiling in which the transfer of DNA may not be attributable to a particular body fluid). The combination and weighting of different kinds of evidence to decide guilt or innocence (of which the DNA evidence is one facet) is a question for the jury.

\section{Interpretation of Mixtures and the Identification of Genetic Anomalies, Stutters, and Other Artifacts}

Powerful methods based on LRs have been developed by Evett et al. (20) and Weir et al. (74) to interpret mixtures. However, these models presuppose the unambiguous identification of 
alleles before analysis and take no account of their relative peak areas. The use of automated sequencer technology makes it relatively simple to collect not only qualitative but also quantitative information (i.e., allele peak height and peak area). When mixtures are simple, originating from two individuals, and the ratio of admixture is less than 1:2, it is possible for the analyst visually to separate the alleles into major and minor components and to use this quantitative information in subsequent interpretation. This is normal practice in our laboratory casework. The method relies on the experience of the expert who uses the rationale outlined by Clayton et al. (15).

Recently, Evett et al. (22) and Gill et al. (37) have suggested a model to assess mixtures, utilizing the information in the peak area. However, the approach also assumes the unambiguous identification of alleles. Gill et al. (33) have introduced a method to interpret mixtures against a background of artifacts (stutters in particular), and this begins the much needed work to model artifacts to aid interpretation. The process of interpretation can undoubtedly be improved by developing new models that form the basis of programmed expert systems.

Usually, a case will comprise several stains, and not all of these may be mixtures. In addition, the proportions of a mixture will often vary across the stain itself. Ambiguity may be resolved by running additional samples. Interpretation is based on the case in its entirety, and the circumstances of the case may allow conditioning to take place.

\section{Use of Guidelines}

The interpretation of mixtures cannot proceed without an understanding of how non-mixtures behave. In multiplexed systems, such as those described by Sparkes et al. (58), mixtures are identified as multiple banded products at each locus. The bands at a locus will often appear unbalanced, with one or more peaks being markedly larger than the others. The presence of artifacts such as stutters (69) in the profile may affect the interpretation.

Before interpreting a potential mixture, it is important to understand the characteristics of heterozygotes and stutters in terms of their peak areas and relative positions. To assist, interpretation guidelines are used (35) that are construed by the analysis of the multiplex characteristics.

The interpretation of mixtures takes into account allelic peak areas or heights and follows a series of steps that are described by Clayton et al. (15). Expert systems based on methods such as those described by Evett et al. (22) are also possible.

A mixture can only be identified if the alleles of the minor component are more than the background noise. In practice, this threshold is approximately 1:10. A mixed profile consisting of more than one individual may be evident if a locus is observed with more than two peaks at a locus. However, extra bands or unbalanced peaks may be genetic or non-genetic. To make an objective assessment of a mixed DNA profile, all of the alternative possibilities should be assessed relative to the knowledge of the characteristics of artifacts.

\section{Stutters}

Whereas the great majority of artifacts can be logically excluded as nonallelic (35), it is not possible to exclude stutters since they are allelic products, differing structurally from the associated allele by just one repeat unit. It follows that a mixture with alleles from a low-level contribution and stutters associated with the major contribution may be equivalent in size and indistinguishable. Although stutters usually appear in pairs, this is not necessarily diagnostic. If an allele has nonconsensus or partial sequences, then it will tend to stutter less than counterparts consisting of complete repeats (69).

An understanding of the characteristics of stutters is an important facet of mixture interpretation. Generally, stutters only become significant when the minor profile is one of evidential significance. In the example shown (Figure 1 ), if $B$ is in a stutter position, then the minor contributor may be $\mathrm{AA}, \mathrm{AB}$, $\mathrm{AC}$, or $\mathrm{AD}$, if $\mathrm{B}$ really is a stutter or $\mathrm{AB}$ if $B$ is not a stutter.

\section{Nonspecific Artifacts}

Nonspecific artifacts are generated as a result of priming from fragments of possibly degraded human or bacterial DNA. When nonspecific artifacts are found within the allelic region, the band shift test described by Gill et al. (36) is particularly useful in excluding nonspecific artifacts; because they have a different sequence to STRs, they usually migrate atypically in the gel.

\section{Software}

A common problem is called "pullup". This is defined as a minor peak in a different color directly below a major allele peak. Typically, a blue peak may pull up a green peak directly below it. This is only problematic if the minor peak is coincident with a potential allele. If there is a possibility, then either singleplexing or a repeat PCR is an option to consider.

\section{Poor Operator Technique}

The most common problem with flatbed gels is the leakage of a sample from one lane into the next. This is read-

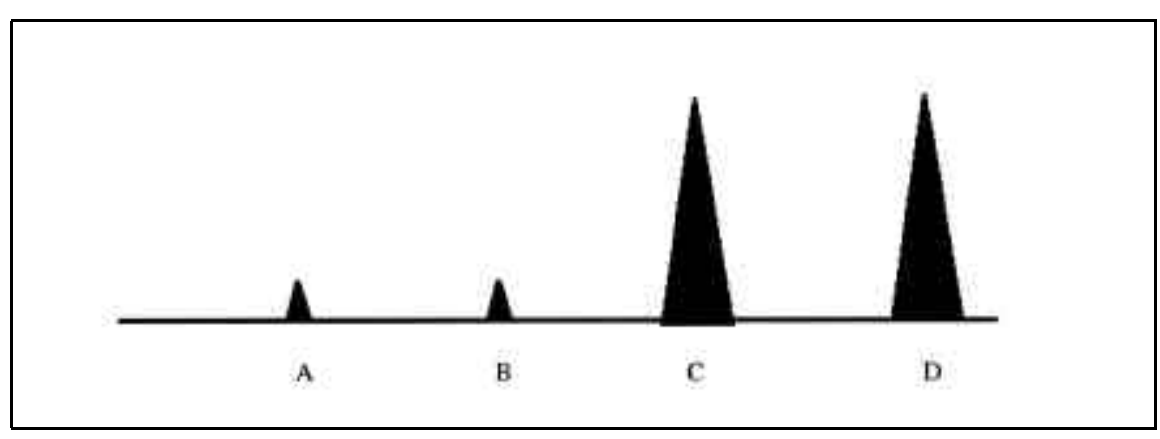

Figure 1. Schematic diagram of a profile comprising two minor bands ( $A$ and $B$ ) and two major bands (C and D). The minor bands are less than 15\% the area of the major bands, and the distance between $\mathrm{B}$ and $\mathrm{C}$ is 1 repeat unit. Consequently, $\mathrm{B}$ could be a stutter. 
ily identified by reference to the scan data in GeneScan ${ }^{\circledR}$ Analysis Software (Applied Biosystems). This is not a problem with CE-based instrumentation.

\section{Masking Effect}

A mixture may not always be evident by the presence of multiple bands. This would occur in cases where the contributors to a mixture actually share alleles at a particular locus. Consider two individuals sharing the same alleles (e.g., D18S51 14,14 and 14,15). If the mixture ratio is $1: 1$, then the ratio of the $14: 15$ peak areas will be $3: 1$, respectively, and pronounced peak asymmetry will be observed.

\section{Suppression of Amplification Efficiency}

Peak-area asymmetry outside the normal range for a non-mixture may occur because of a primer binding site mutation. This has the effect of altering annealing and melting temperatures, which changes the amplification efficiency and decreases the resulting signal. If a substitution mutation occurs at the $3^{\prime}$ end of the primer, then a mismatch will result and amplification will fail completely, resulting in a null allele. The closer the substitution is to the $5^{\prime}$ end of the primer, the less the effect on the amplification efficiency.

\section{Genetic Anomalies}

Trisomy or translocations. Both chromosome and gene duplications affect all cells in an individual. In practice, it is impossible to tell the difference without resorting to genetic analysis. If duplication is accompanied by a deletion or insertion of a repeat unit, then three bands of similar size are generated (Figure 2).

If a gene is duplicated without additional mutation, then only two bands are visible in a $2: 1$ ratio. In the example in Figure 3, an XYY individual has a double dose of the Y gene. Note that other loci are balanced, and this argues against the possibility of a mixture. In the multiplex described by Sparkes et al. (58), trisomy or translocation was observed in 1 in 2000 samples at each locus.

\section{Somatic Mutation}

If a somatic mutation occurs during embryological development, then two types of cells with different genotypes may coexist, and this leads to a threebanded profile (Figure 4). The peak areas will depend on the relative proportion of the mutant cell and will not be equivalent. This is arguably the most difficult condition to elucidate because it is possible that not all tissues will demonstrate somatic mutation. The incidence of somatic mutation is variable-out of
120000 samples, not one has been observed at the HUMTH01 locus, whereas the incidence is approximately 1 in 5000 at the D18S51 and HUMFIBRA loci. It is possible that some somatic mutations will be indistinguishable from stutters; therefore, these figures are probably underestimates because they are only recorded if unambiguous.

The genetic phenomena described (trisomy, translocation, and primer binding site mutations) can be verified by the analysis of the reference sample, which should also demonstrate the same anomaly unless a tissue-specific somatic mutation has occurred. In the latter case, confirmation may depend on a reference sample that has the same origin as the case stain, although we cannot completely rule out the possibility that the appearance of somatic mutations could vary over time within tissues such as the buccal lining, which consists of rapidly dividing cells.

To summarize, an understanding of the behavior of the DNA profiling system is important to assess potential mixtures. Loci will behave somewhat differently from each other, but it is possible to generalize. Here are some of the key features: $(i)$ the smallest peak area of a heterozygote will usually be greater than $60 \%$ of the size of its partner (peak area or peak height); (ii) within the previous guideline, the high molecular weight peak is often smaller than the low mol-

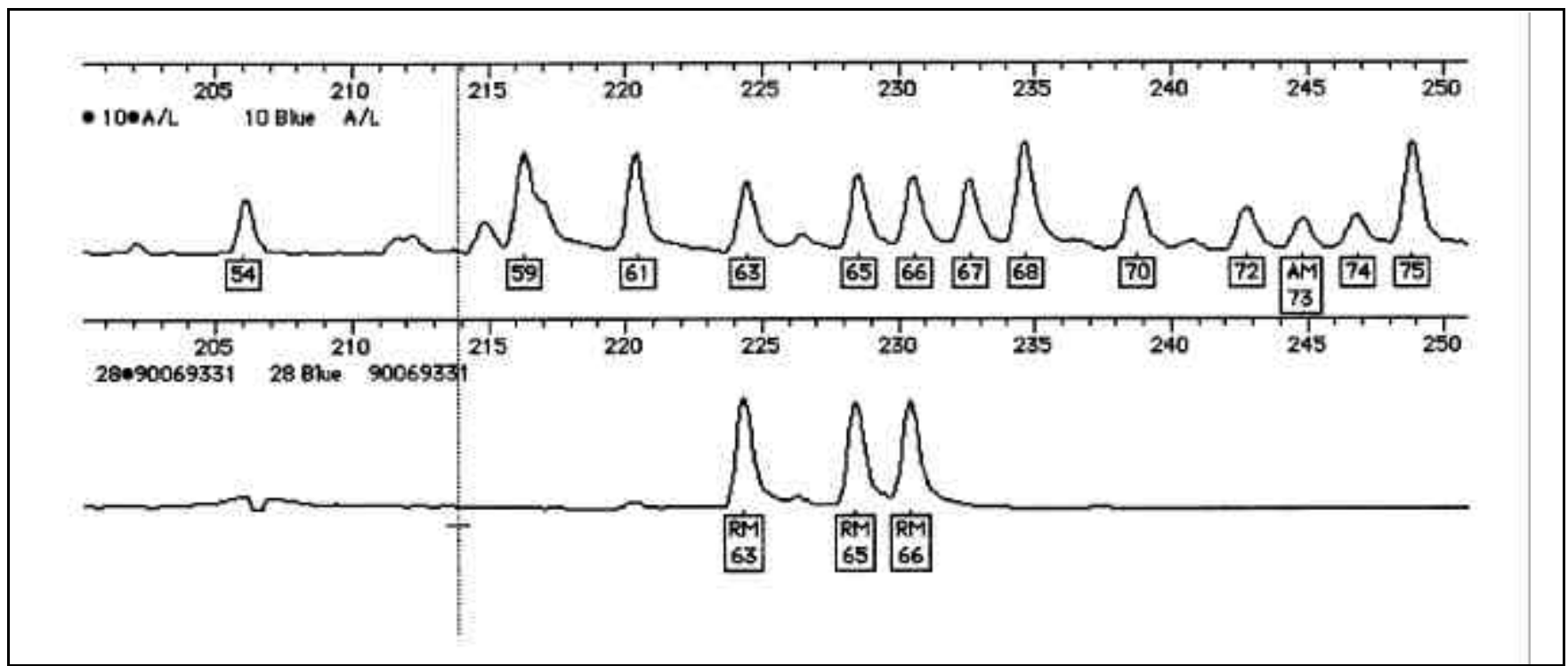

Figure 2. An example of trisomy showing three different alleles. D21S11 trisomy or translocation in the lower pane. Note that the bands are equivalent in size. Allelic ladder in the upper pane. AmpFISTR SGM Plus system. 
ecular weight peak since PCR amplifies the latter the most efficiently; (iii) stutter peaks are usually less than $15 \%$ of the area of the associated allelic peak; (iv) stutters are 1 repeat unit (e.g., 4 bp for tetramerics) shorter than the associated allele; and (v) genetic anomalies such as trisomy are usually rare and consequently restricted to a single locus. The exam ination of the reference control is useful to resolve features.

\section{LOW COPY NUMBER DNA PROFILING}

The development of the PCR technique $(48,49,53)$ was responsible for a dramatic increase in the sensitivity of the DNA profiling technique and enabled the analysis of much smaller amounts of DNA than had previously been possible. The actual amount of DNA required for analysis was decreased by approximately 1000-fold. Samples amplified by PCR between $250 \mathrm{pg}$ and $1 \mathrm{ng}$ are routinely analyzed, compared with (50 ng to $1 \mu \mathrm{g}$ ) when minisatellites were used.

\section{Increased Range of Evidence Types}

The improved sensitivity also led to an increase in the kind of different evidence types that could be analyzed, concurrently improving the success rates of DNA profiling techniques on evidence types that had previously proven to be problematic or largely unsuccessful. For example, the analysis of saliva was demonstrated on cigarette butts (40), envelope flaps, and stamps. It was also demonstrated that DNA profiles could be recovered from saliva associated with bite marks (62) and from debris underneath fingernails (70). When DNA degrades, it decomposes into short fragments; hence, conventional Southern blotting techniques are not very successful because minisatellites are typically greater than $1 \mathrm{~kb}$. On the other hand, the sizes of STRs that are analyzed are typically between 150 and 450 bases. The size of DNA fragments that could be analyzed was very much smaller than those used with non-PCR techniques.

Controlled studies by Frank and Llewellyn (27) demonstrated the efficacy of STR DNA analysis on bone sam ples up to 18 months old and muscle or bone marrow up to 8 weeks old that were maintained at ambient temperature. Hoff-Olsen et al. (41) successfully analyzed DNA from bodies up to 90 days after death-noting that the success rate for shorter STRs was improved. This suggests that primers redesigned to be closer to the tandem repeating region of the STR may further improve the efficacy of STR analysis on highly degraded DNA.

The utility of STRs to analyze highly degraded DNA samples in real casework was dramatically demonstrated by the identification of human remains from disasters such as Waco, Texas (13, 14,76), the Spitsbergen disaster (52), TWA flight 800 (6), Swissair flight 111 (R. Fourney, personal communication), and the 1998 Philippines air crash (39). However, Olaisen et al. (52) were able to use minisatellites in the Spitsbergen disaster with a $100 \%$ success rate because, before collection, the bodies were at an ambient temperature of approximately $0^{\circ} \mathrm{C}$ and were well preserved. Conversely, with the Waco disaster, the bodies were badly burned and

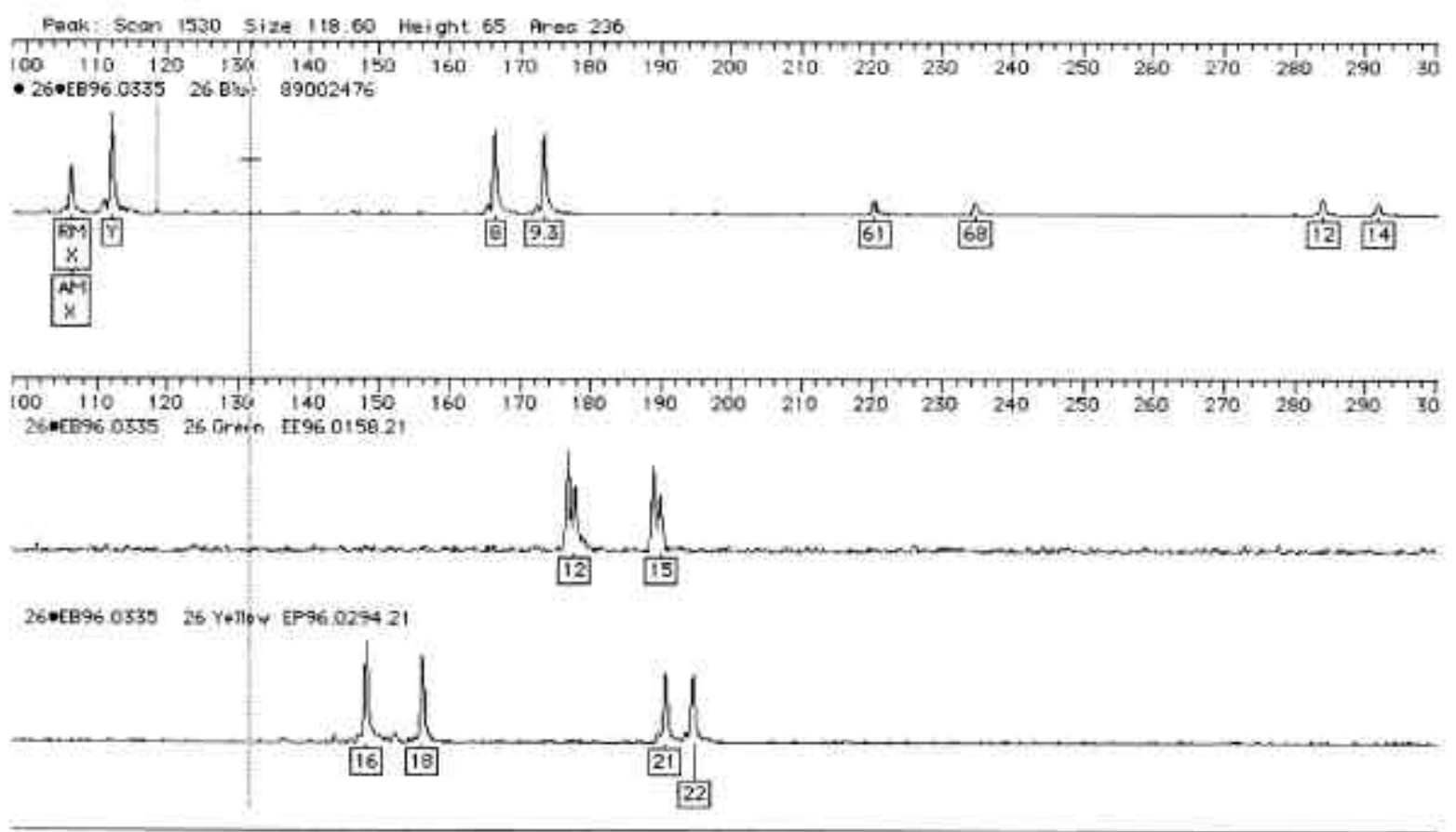

Figure 3. An example of trisomy with two different alleles. XYY individual, upper pane left, showing a Y peak twice the size of the X peak. The remaining loci of the multiplex are balanced. AmpFISTR SGM Plus system. The loci are as follows from left to right: upper trace, amelogenin, HUMTHO1, D21S11, and D18S51; middle trace, D8S1179; lower trace, HUMVWA and HUMFIBRA. 
subsequently highly decomposed after several days at an ambient temperature of approximately $30^{\circ} \mathrm{C}$; hence, minisatellite analysis was not possible with these samples. The success rate (with STRs) was $66 \%-83 \%$. A similar success rate was achieved with the TWA flight 800 disaster where bodies were decomposed and often skeletonized.

One area that has received much attention is the use of fingerprint enhancement chemicals on bloody fingerprints. For example, Fregeau et al. (29) showed that the chemicals tested had no adverse effect on PCR provided that stains were less than 54 days old. Andersen and Bramble (1) also demonstrated that light sources used to enhance bloody fingerprints did not affect the success of PCR provided that shortwave UV was not used.

The retrieval of DNA profiles from non-bloody hand or fingerprints where no body fluid was apparent began a new area of the exploitation of the DNA profiling technique. Van Oorschot et al. (65) recovered DNA profiles from surfaces that had been touched, such as the handles of leather briefcases and telephone handsets (primary transfer); furthermore, the amount of DNA that could be recovered by swabbing was surprisingly high. Between 2 and 150 ng were estimated; this allowed analysis using conventional STR techniques. In addition, it was claimed that DNA could be transferred from an object to a per- son's hands (secondary transfer). How ever, following a similar experimental design, Ladd et al. (45) were only able to recover 1-15 ng from surfaces; the secondary transfer from individuals consisted of DNA profiles that were close to background and was considered to be uninterpretable. Van Renterghem et al. (66) were able to analyze partial profiles (or better) from 38 out of 116 fingerprints lifted from glass slides using conventional analysis with AmpFlSTR Profiler Plus.

\section{Increasing the Sensitivity by Increasing the PCR Cycle Number}

Generally, the lower limits of sensitivity recommended by manufacturers of STR multiplex systems are in the region of $250 \mathrm{pg}$. Multiplexes usually work at their optimum efficiency when $1 \mathrm{ng}$ DNA is analyzed $(57,58)$ and not more than 28-30 amplification cycles are carried out. The interpretation of DNA profiles is assisted by using systems that are not too sensitive, and this is important because the scientist often needs to associate the presence of a bloodstain (or other evidence) with the DNA profile itself. A highly sensitive system that may reveal DNA from sources other than the body fluid analyzed would require careful consideration when the evidence was interpreted. For this reason, validation exercises often include studies on the effect of

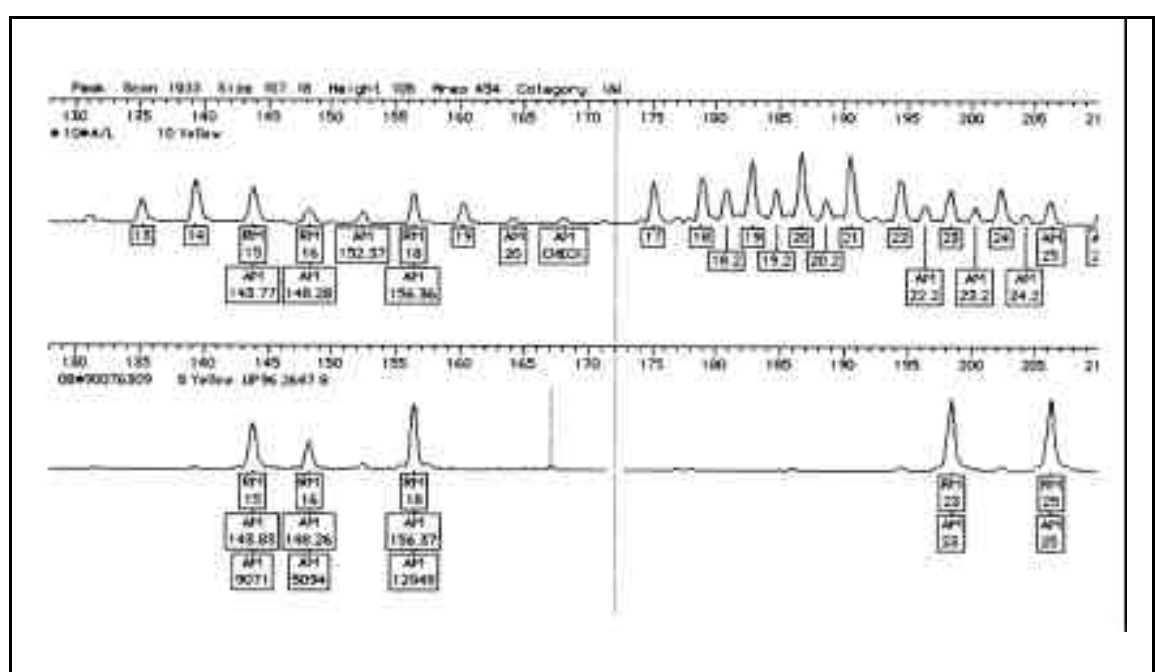

Figure 4. An example of somatic mutation. Somatic mutation of HUMVWFA31, lower left panel. Note three peaks are present of different sizes. HUMFIBRA/FGA peaks are shown on the right side. The upper panel shows HUMVWFA31 and HUMFIBRA/FGA allelic ladders. AmpFISTR SGM Plus system. 
Table 2. Results of Six Replicate PCR Tests of a Sample Under Low Copy Number Analysis Conditions Compared to the Control Sample

\begin{tabular}{|c|c|c|c|c|c|c|c|c|c|c|c|}
\hline & Amelo & D19 & D3 & D8 & THO & VWA & D21 & FGA & D16 & D18 & D2 \\
\hline CONTROL & $x \times$ & 14,14 & 18,18 & 15,15 & 79.3 & 19,19 & 2832.2 & 20,23 & 9,12 & 12,16 & 17,23 \\
\hline \multicolumn{12}{|l|}{ Sample } \\
\hline 1 & -- & $14 \mathrm{~F}^{\prime}$ & -- & $15 \mathrm{~F}^{\prime}$ & -- & -- & 2832.2 & $20 \mathrm{~F}^{\prime}$ & -- & $16 \mathrm{~F}^{\prime}$ & -- \\
\hline 2 & $X F^{\prime}$ & -- & $18 \mathrm{~F}^{\prime}$ & $15 \mathrm{~F}^{\prime}$ & -- & $19 \mathrm{~F}^{\prime}$ & -- & - & $12 F^{\prime}$ & -- & -- \\
\hline 3 & $X F^{\prime}$ & -- & -- & $15 \mathrm{~F}^{\prime}$ & -- & -- & -- & - & -- & -- & $17 \mathrm{~F}^{\prime}$ \\
\hline 4 & $X F^{\prime}$ & $14 \mathrm{~F}^{\prime}$ & $18 \mathrm{~F}^{\prime}$ & -- & -- & -- & -- & - & 912 & -- & -- \\
\hline 5 & $X F^{\prime}$ & -- & $18 \mathrm{~F}^{\prime}$ & -- & -- & $18 \mathrm{~F}^{\prime}$ & -- & - & -- & -- & -- \\
\hline 6 & $X F^{\prime}$ & $14 F^{\prime}$ & -- & -- & -- & $19 \mathrm{~F}^{\prime}$ & 2832.2 & $20 \mathrm{~F}^{\prime}$ & -- & $12 F^{\prime}$ & -- \\
\hline Consensus & $X F^{\prime}$ & $14 \mathrm{~F}^{\prime}$ & $18 \mathrm{~F}^{\prime}$ & $15 \mathrm{~F}^{\prime}$ & -- & $19 \mathrm{~F}^{\prime}$ & 2832.2 & $20 \mathrm{~F}^{\prime}$ & $12 \mathrm{~F}^{\prime}$ & -- & -- \\
\hline
\end{tabular}

rough handling, coughing, or sneezing onto garments to determine if it is possible to transfer DNA casually to evidential material.

Nevertheless, forensic scientists always seek to increase the sensitivity of their methods, and the easiest way to do this is simply to raise the number of PCR amplification cycles. Findlay et al. (24) demonstrated that single cells (buccal) could be analyzed when 34 cycles were used with the SGM multiplex system. The interpretation was not straightforward-additional alleles were observed, the sizes of stutters were enhanced, and allele drop-out was com mon. However, such profiles may be interpreted using robust guidelines. Subsequently, increasing the sensitivity of PCR by raising the number of cycles has been used to increase the range of evidence types analyzed. For example, Wiegand and Kleiber (71) and Wiegand et al. (72) analyzed epithelial cells that were transferred from an assailant after strangulation using 30-31 PCR cycles. Van Hoofstat et al. (64) analyzed fingerprints from grips of tools with 28-40 cycles. Barbaro et al. (8) reported the analysis of STRs from hair shafts in the absence of the roots using 35-43 cycles.

Increased PCR cycles are routinely used by anthropologists and forensic scientists to identify ancient DNA from bones. Gill et al. (32) used 38-43 cycles to analyze STRs from 70-year-old bone from the Romanov family. Schmerer et al. $(54,55)$ and Burger et al. (11) analyzed STRs from bone that was thou- sands of years old (60 and 50 PCR cycles, respectively). Some authors have used modified PCR methods; for exam ple, a nested primer PCR strategy was used by Strom and Rechitsky (60). This utilized a first-round amplification with 40 cycles, with subsequent analysis of a portion with an additional 20-30 cycles. This method was used to analyze DNA from charred human remains and minute amounts of blood.

Gill et al. (38) compared different methods available to analyze DNA less than $100 \mathrm{pg}$, varying cycling conditions between 28 and 60 cycles and concluding that the optimum for both SGM and AmpFlSTR SGM Plus systems was 34 cycles. There was little to be gained by increasing the cycle number further since it did not result in increased sensitivity but encouraged artifact production. The extreme sensitivity of the method suggested that analysis should only be attempted in a sterile environment to reduce the possibility of contamination from personnel within the laboratory itself.

Nevertheless, all methods used to analyze low copy number DNA suffer from several disadvantages that are primarily derived from stochastic variation. When present in low copy number DNA, a molecule that is amplified by chance during the early rounds of the PCR is likely to be preferentially amplified. Therefore, there are several consequences that cannot be avoided: $(i)$ allele drop-out may occur because one allele of a heterozygote locus can be preferen- tially amplified; (ii) stutters may be preferentially analyzed-these are sometimes known as false alleles; (iii) the method is prone to sporadic contamination, amplifying alleles that are unassociated with the crime stain or sample.

This means that different DNA profiles may be observed after replicate PCR analyses. Tarbelet et al. (63) suggested a method of replicated analyses that comprised a rule that an allele could only be scored if observed at least twice in replicate samples. This theory was expanded by Gill et al. (38), who adopted Tarbelet's duplication rule and demonstrated that it was conservative in relation to a new LR method that assessed DNA profiles in relation to sporadic allelic contaminants, stutters, and allelic drop-out. Provided that the level of sporadic contamination was not high ( $<30 \%$ per locus), the duplication method was demonstrated to be conservative relative to the LR method.

Table 2 gives an example of the derivation of a consensus sequence. The $\mathrm{F}^{\prime}$ designation means that allele dropout may have happened. For each locus, the LR is calculated as $1 / 2 f a$, where $f a$ is the match probability of the observed allele. If there is no evidence of drop out at a locus that is heterozygous (e.g., D21), then the LR is calculated as $1 / 2 f a f b$, where $f b$ is the match probability of the second allele. An example of a spurious contaminant is observed at the VWA locus. However, this does not affect the interpretation since there is only one example and it was 
not observed in the negative control. The overall LR for the sample is calculated by multiplying the individual LRs together. Gill et al. (38) outlined the alternative method of calculation, which incorporates the effect of stutter and allele drop-out into the actual calculation. With most low copy number examples, it is only possible to carry out a maximum of three replicate tests because the sample size is limiting.

\section{Quantification of DNA and Interpre- tation of Evidence}

Generally, there are two different methods that are used to estimate the quantity of DNA in a forensic sample: either (i) the dot blot method (68), which has the advantage that it is human specific, or (ii) the use of dyes that intercalate with dsDNA and fluoresce, such as PicoGreen ${ }^{\circledR}(56)$. If quantification indicates that the amount of DNA recovered is very low $(<100 \mathrm{pg})$, then LCN protocols may be utilized (depending on the case circumstances).

\section{Association of the DNA Profile with the Evidential Material Analyzed}

There are two broad categories of evidence types-discrete (e.g., bone and hair) and non-discrete (e.g., bloodstains). When using low copy number DNA profiling, it is generally easier to associate a DNA profile with a discrete evidence type. This is because analysis of bone samples is not attempted without removing the outermost layer by physical methods (e.g., sandpaper) to minimize the possible contamination from modern DNA. Similarly, hair shafts can be washed in a detergent solution to remove adhering DNA. This cannot be done with evidence types that are not discrete (e.g., bloodstained cloth); hence, the chance is increased that a DNA profile may not be directly associated with the evidential body fluid that is "apparently" analyzed. Because there is a serious possibility of transferring low copy number DNA from a modern source, we use the following guidelines to either minimize the chance of contamination or to identify an occurrence: (i) DNA extractions and reaction setups are carried out in a dedicated laboratory; (ii) personnel wear dispos- able laboratory coats, gloves, and face masks; (iii) benches and equipment are frequently treated with bleach (or the equivalent) and irradiated with UV light; (iv) PCR amplification is carried out in a separate laboratory or area; $(v)$ negative controls are used with every test to demonstrate the absence of contamination; (vi) PCR tests are duplicated whenever possible; (vii) all results are compared against a staff database; and (viii) a database to eliminate the crimescene investigators as potential contributors is also under preparation.

\section{Defining when DNA Transfer Can Occur}

Consider a general model to illustrate the potential transfer of DNA before, during, and after a crime (Figure 5). Before and after a crime event, there is the potential for the adventitious transfer of cells. Note that the term contamination is reserved for the transfer of DNA after the crime event. Adventitious transfer and laboratory contamination usually involve low levels of DNA.

The association of body fluid and the DNA profile is not implicit. If the body fluid giving a positive presumptive test is small or degraded, then the DNA profile may have originated from an alternative source. For example, a small, degraded blot spot that has given a positive presumptive test for blood might be masked by a fresh saliva stain that, instead, contributes to the observed result. The scientist cannot infer either the type of cell donating the DNA or the time when the cells were deposited.

An estimate of the quantity of DNA is useful to assist in the interpretation of the relevance of a DNA profile. For example, if a visible, fresh bloodstain yields several micrograms of DNA, then it is not unreasonable to associate the DNA profile with the bloodstain. However, the association is uncertain if the bloodstain is minute, old, and yields just a few picograms of DNA. Inevitably, there is a direct relationship between the quantity of DNA present and the relevance of the evidence. The interpretation of the case can only follow after an assessment of all the available evidence, taking into consideration the scenarios offered by the prosecution and defense lawyers. 


\section{Assessment of Contamination Risks}

Figure 5 shows that DNA can be transferred at any time before during and after the crime. The foregoing discussion has covered the possibility of adventitious transfer at a period before the crime, and it is implicit that the DNA profile matches a suspect. If the DNA profile does not match the suspect, then post-crime transfer must be considered. Contamination is the transfer of DNA after the crime event. Potential sources of contamination are $(i)$ the investigative officers and pathologists at the crime scene, (ii) the laboratory staff, (iii) cross-contamination from samples processed in the laboratory (e.g., by aerosol), and (iv) plasticware contamination (contaminated at the manufacturing source).

Whereas ( $i$ ) and (ii) can be covered by reference to staff databases and the databases of investigating officers, (iii) and (iv) are more difficult to detect but are minimized by good laboratory design, the use of anti-contamination clothing and facemasks, and the UV sterilization of plastic-ware.

The transfer of DNA by individuals unassociated with the crime, before the crime event itself, is defined as adventitious transfer. When a DNA profile does not match the suspect, the following possibilities apply: $(i)$ the suspect is not the source, and the perpetrator profile has been visualized; (ii) the cells have been transferred by an innocent individual before the crime (perpetrator has not shed the cells)-adventitious transfer; or (iii) the cells have been transferred by an investigator after the crime event (perpetrator has not shed cells) - contamination. Note that mixtures may show DNA profiles arising from a combination of the three different events listed.

The victim's circumstances leading up to the crime event are unknown to the scientist; hence, the possibilities of adventitious transfer cannot be directly ascertained. Once the crime has been discovered, the scene and the associated evidence enter a controlled environment, where the risk of contamination is minimized by the adoption of good laboratory and investigative practice.

The primary risk of contamination is wrongful exclusion-particularly if the contaminant masks the perpetrator's profile. For the converse to apply, wrongful inclusion, either tube mix-up or gross contamination (e.g., the use of pipet tips contaminated in the laboratory-for instance, used twice) would be required. Good laboratory practice renders this a virtual impossibility and is not considered further here.

\section{Purpose of Negative Controls}

The negative control acts as a control of gross contamination; that is, it detects a contamination event that has affected one of the reagents used in the extraction or the PCR process itself. Such a contaminant will affect several lanes of the gel.

The negative control also acts as a general "health check" of the system. A spurious contaminant, defined as a few cells or even fragments of chromosomes that affect only one tube in a batch, may be introduced in aerosol or plastic-ware. By definition, at the molecular level, the negative control cannot be used to assess whether samples in an associated batch have been contaminated. The possibility of direct operator transfer is controlled by the comparison of profiles against the staff databases. Negative controls are always prepared in duplicate for every series of tests. If an allele is observed in both negative controls, then this could indicate a higher than normal level of contamination rate for that particular allele, and this observation would prevent the reporting of that allele, while others would be unaffected. In a sterile environment, contamination manifests itself as spurious alleles that usually appear alone (38). Futhermore, contamination appears randomly so that multiple alleles will be observed over a period of time. Currently, we model the chance of observing a spurious allele the same as the frequency in the general population. We theorize that contaminants observed in sterile environments are probably derived from fragments of chromosomes that are present in aerosol wherever people are present. The level of contamination is continually monitored by reference to the negative controls. These data are used to assess the chance that a spurious allele will appear in a non-control sample. The chance that a spurious allele appears in a negative control is the same as the chance of it appearing in a non-control sample.

\section{Transfer and Persistence}

There is currently a considerable lack of understanding about the issues of transfer and persistence. Further work is being undertaken in this area. The ways by which DNA may be transferred to objects can be subdivided into two categories, primary transfer and secondary transfer.

Primary transfer occurs when DNA is transferred as a result of physical

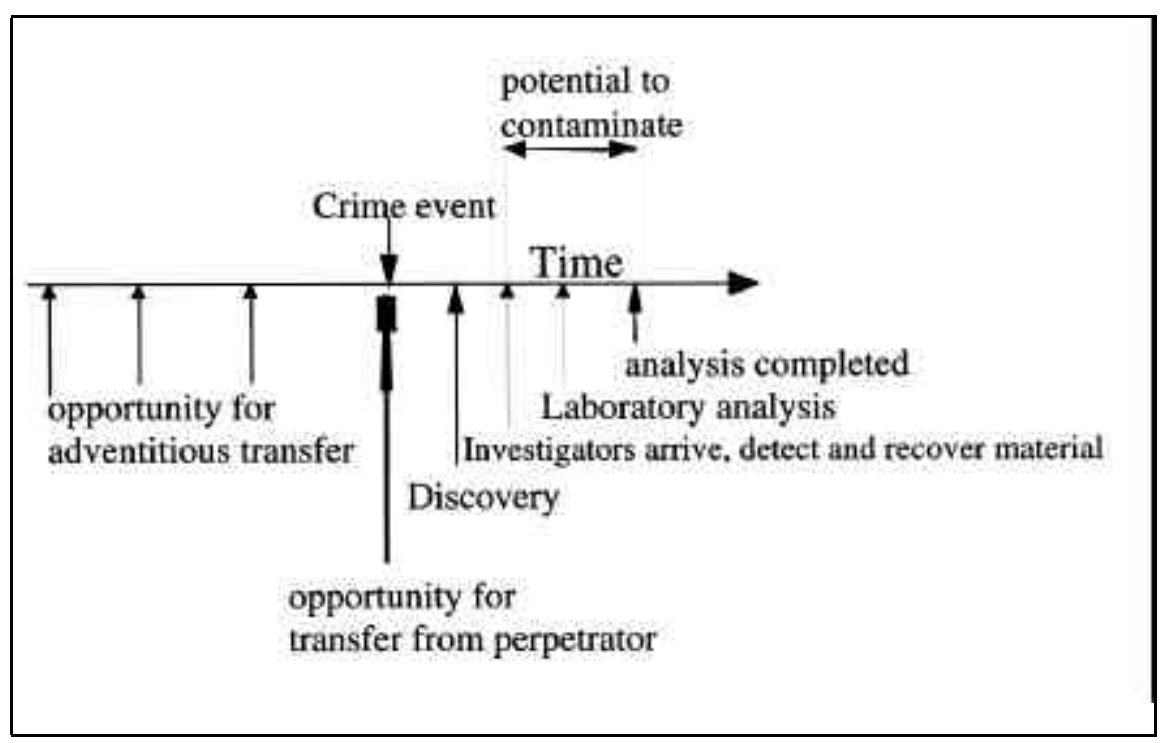

Figure 5. A timeline illustrating the potential for DNA transfer. 
contact. There is a marked variation between the extents that different individuals shed DNA from physical contact with objects (unpublished results). The amount of DNA remaining at a crime scene may depend on the time since contact, with the best chance of recovery immediately after an incident. The persistence of DNA will also depend on the extent of contact by other individuals.

Secondary transfer occurs when DNA of a person ( $x$ ) is transferred to an object by a different person (y). This may occur if the suspect and victim have physical contact (e.g., shake hands). Secondary transfer may also occur if two objects are in contact. Currently, there is some evidence (unpublished data) to support the secondary transfer from person to object, although only mixtures have been encountered so far. There is currently no evidence to support the secondary transfer between objects. Experimentation is under way to evaluate secondary transfer.

\section{Current Reporting of Sub-Level 1 Propositions in Statements}

In conjunction with the increased use of DNA profiling, there has been a parallel development in the interpretation methodology. In particular, Cooke et al. $(16,17)$ and Evett et al. (23) introduced the notion of the "hierarchy of propositions". This has led to a much deeper understanding of the interpretative process. Because of the uncertainties that surround persistence and transfer, the statements are written to reflect this. Examples of the wording used in statements are given below. Interpretation depends on a full analysis of the circumstances of the crime and is based on a careful consideration of all of the non-DNA evidence.

Observation of mixtures. With low copy number DNA profiling, mixtures are commonly encountered. It cannot be determined whether recovered DNA profiles are associated with a crime event. An example statement follows. "The observation of mixed DNA STR profiles (i.e., from more than one individual) can be anticipated. For example, from past experience, it is not unusual to detect DNA profiles on items that match the profile of an individual who has habitually worn that item. However, currently, we have no information to assist with questions of transfer and persistence of low levels of DNA on items such as clothing. Thus, consideration should be given as to how the DNA detected has been transferred to that item and, consequently, to the relevance of finding profiles matching the individuals in the case".

In the following statement, two alternatives are considered. No reference is made about the origin of the body fluid type; it is simply stated that DNA was recovered from the item. "Either the majority of the DNA originated from Mr. X or the majority of the DNA originated from someone other than and unrelated to Mr. X. If this DNA had, in fact, originated from Mr. X, then I would expect to obtain matching profiles."

In the summary section, the follow ing paragraphs are included. This statement was specifically written for a case in which DNA from a watchstrap matched a suspect.

When very small amounts of DNA are analyzed, special considerations arise as follows. (i) Although a DNA profile has been obtained, it is possible neither to identify the type of cells from which the DNA originated nor to state when the cells were deposited. (ii) It is not possible to make any conclusion about the transfer and persistence of DNA in this case. It is not possible to estimate when the suspect last wore the watch-if it is his DNA. (iii) Because the DNA test is very sensitive, it is not unexpected to find mixtures. If the potential origins of DNA profiles cannot be identified, then it does not necessarily follow that they are relevant to this case. Cell transfer can occur as a result of casual contact.

Effectively, the strength of the low copy number DNA evidence is decreased compared with conventional DNA analysis. This inevitably arises from the uncertainties relating to the method of DNA transfer to a surface and when the DNA was transferred. It is emphasized that the relevance of the DNA evidence in a case can only be assessed by a concurrent consideration of all the non-DNA evidence. Research is currently being undertaken to devise a probabilistic Bayesian method that encapsulates the DNA and non-DNA evidence.

\section{CONCLUSIONS AND PERSPECTIVES}

\section{Standardization}

STRs are undoubtedly the most im portant genetic markers to be used in forensic science because they form the basis of national intelligence databases throughout the world. Hence, standardization between laboratories is of fundamental importance, not only within countries but also between countries that need to investigate a cross-border crime. This has led to the development of commercial multiplexed systems that comprise loci that have been agreed upon by working groups that consider standardization (e.g., European Network of Forensic Science Institutes). For example, in the US, there are 13 STR loci used by the CODIS system, whereas there are seven STRs plus amelogenin in Europe. The seven European STRs loci are all included in the CODIS system. The nomenclature has been standardized, assisted by the availability of sequenced allelic ladder controls.

\section{Analysis of Mixtures and Expert Systems}

One of the more difficult aspects of STR interpretation is the analysis of mixtures. The original models took no account of peak area and consequently presupposed unambiguous identification of alleles before analysis. The use of automated sequencer technology made it relatively simple to collect qualitative and quantitative information (i.e., allele peak height and peak area). When mixtures are simple, originating from two individuals, and the ratio of admixture is less than $1: 2$, it is possible for the analyst to separate the alleles visually into major and minor components and to use this quantitative information in subsequent interpretation. The interpretation of the minor components of mixtures is complicated by PCR artifacts such as stutters. These are, by definition, in allelic positions and are consequently indistinguishable from true alleles. New methods utilize the information of the peak area. The process of interpretation can undoubtedly be improved by developing new 
models that form the basis of programmed expert systems.

\section{Low Copy Number DNA Profiling}

The recent innovation of low copy number DNA profiling using STRs has resulted in an expansion of the range of evidence types that may be analyzed. However, the interpretation of DNA profiles against a background of contamination, allelic drop-out, and enhanced stutter is not straightforward and requires a consideration of the primary and secondary transfer effects. Once again, expert systems may be able to assist the interpretative process.

\section{Other DNA Markers}

It is important not to lose sight of other innovations. In particular, the special properties of mtDNA (being present in high copy number per cell) are used to analyze very old and degraded materials such as bones and hair shafts. In addition, markers are being developed that actually tell us something about the individual, such as race and hair color. Recently, markers to the Y chromosome have been developed, primarily to assist with the interpretation of male/female mixtures in which the former is in particularly low concentration. However, the major disadvantage of systems other than core STR loci is that they cannot be used in conjunction with intelligence databases; hence, this provides a stimulus to continually im prove the utility and sensitivity of STRs, as demonstrated by the development of low copy number techniques.

Once particular STR loci have been chosen to form the core system of a national DNA database, then there are considerable implications if it is decided to move to a new genetic system. Currently, the only contender is single- nucleotide polymorphism (SNP) analysis. For this to be a realistic alternative, the advantages in cost and ease of use will have to be demonstrated.

There will be changes in the platforms used to analyze STRs. Currently, both flatbed gel and capillary gel formats are used. For high-throughput laboratories, there are obvious attractions to using 96-CE machines. Concurrent developments also include the automation of extraction, quantification, PCR setup, PCR, and post-PCR setup. In addition to these developments, the interpretation is also currently the subject of developing expert systems that will effectively result in the substantial automation of the entire process from start to finish. Looking further to the future, platform development will result in faster, cheaper methods, particularly in relation to the miniaturization that may enable analysis at the scene of a crime.

Finally, looking back to 1986 , when 
the first seeds were sown that led to the exponential growth of DNA profiling, it has been shown that its initial promise as a major investigative tool has been realized in ways that could not have been predicted at the time. STRs have led to a massive change in the way in which forensic science is used by the police; in particular, the expansion of DNA analysis to include both serious crimes and petty crimes such as burglary has resulted in the strategic use of DNA to actively reduce crime levels (i.e., by virtue of increasing detection rates and acting as a deterrent). This means that DNA profiling will be firm ly on the political agenda for the foreseeable future.

\section{ACKNOWLEDGMENTS}

I am grateful to Cassie Shaw, Dave Werrett, Jonathan Whitaker, and John Buckleton for their constructive criticism of the manuscript.

\section{REFERENCES}

1.Andersen, J. and S. Bramble. 1997. The effects of fingermark enhancement light sources on subsequent PCR-STR DNA analysis of fresh bloodstains. J. Forensic Sci. 42:303-306.

2.Balding, D.J. 1999. When can a DNA profile be regarded as unique? Sci. Justice 39:257260.

3.Balding, D.J. and P. Donnelly. 1996. Evaluating DNA profile evidence when the suspect is identified through a database search. J. Forensic Sci. 41:603-607.

4.Balding, D.J., M. Greenhalgh, and R.A. Nichols. 1996. Population genetics of STR loci in Caucasians. Int. J. Legal Med. 108:300-305.

5.Balding, D.J. and R.A. Nichols. 1994. DNA profile match probability calculation: how to allow for population stratification, relatedness, database selection, and single bands. Forensic Sci. Int. 64:125-140.

6.Ballantyne, J. 1997. Mass disaster genetics. Nat. Genet. 15:329-331.

7.Bar, W., B. Brinkmann, B. Budowle, A. Carracedo, P. Gill, P. Lincoln, W. Mayr, and B. Olaisen. 1997. DNA recommendations. Further report of the DNA Commission of the ISFH regarding the use of short tandem repeat systems. International Society for Forensic Hemogenetics. Int. J. Legal Med. 110:175-176.

8.Barbaro, A., G. Falcone, and A. Barbaro. 2000. DNA typing from hair shaft. Prog. Forensic Genet. 8:523-525.

9.Budowle, B., R. Chakraborty, G. Carmody, and K.L. Monson. 2000. Source attribution of a forensic DNA profile. Forensic Science Communications (http://www.fbi.gov/ programs/lab/fsc/backissu/july2000/source. htm).

10. Bıdowle, B., T.R. Moretti, A.L. Baumstark, D.A. Defenbaugh, and K.M. Keys. 1999. Population data on the thirteen CODIS core short tandem repeat loci in African Americans, U.S. Caucasians, Hispanics, Bahamians, Jamaicans, and Trinidadians. J. Forensic Sci. 44:1277-1286

11.Burger, J., S. Hummel, B. Hermann, and W. Henke. 1999. DNA preservation: a microsatellite-DNA study on ancient skeletal remains. Electrophoresis 20:1722-1728.

12.Chakraborty, R., D.N. Stivers, B. Su, Y. Zhong, and B. Budowle. 1999. The utility of STR loci beyond human identification: implications for the development of new DNA typing systems 1999. Electrophoresis 20:16821696.

13.Clayton, T.M., J.P. Whitaker, D.L. Fisher, D.A. Lee, M.M. Holland, V.W. Weedn, C.N. Maguire, J.A. DiZinno et al. 1995. Further validation of a quadruplex STR DNA typing system: a collaborative effort to identify victims of a mass disaster. Forensic Sci. Int. 76:17-25.

14.Clayton, T.M., J.P. Whitaker, and C.N. Maguire. 1995. Identification of bodies from the scene of a mass disaster using DNA amplification of short tandem repeat (STR) loci. Forensic Sci. Int. 76:7-15.

15.Clayton, T.M., J.P. Whitaker, R. Sparkes, and P. Gill. 1998. Analysis and interpretation of mixed forensic stains using DNA STR profiling. Forensic Sci. Int. 91:55-70.

16.Cooke, R., I.W. Evett, G. Jackson, P.J. Jones, and J.A. Lambert. 1998. A hierarchy of propositions: deciding which level to address in casework. Sci. Justice 38:231-239.

17.Cooke, R., I.W. Evett, G. Jackson, P.J. Jones, and J.A. Lambert. 1999. Case pre-assessment and review in a two-way transfer case. Sci. Justice 39:103-111.

18.Cotton, E.A., R.F. Allsop, J.L. Guest, R.R.E. Frazier, P. Koumi, I.P. Callow, A. Seager, and R.L. Sparkes. 2000 Validation of the Amp $f$ STR SGM plus system for use in forensic casework. Forensic Sci. Int. 112:151161.

19.DNA Advisory Board. 2000. Statistical and population genetics issues affecting the evaluation of the frequency and occurrence of DNA profiles calculated from pertinent population databases. Forensic Science Communications 2.(http://www.fbi.gov/hq/lab/fsc/backissu/july 2000/dnastat.htm).

20.Evett, I.W., C. Buffery, G. Willot, and D.A. Stoney. 1991. A guide to interpreting single locus profiles of DNA mixtures in forensic cases. J. Forensic Sci. 31:41-47.

21.Evett, I.W. and B.S. Weir. 1998. Interpreting DNA evidence, p. 39-42. In Statistical Genetics for Forensic Scientists. Sinauer Associates, Sunderland, MA.

22.Evett, I.W., P. Gill, and J.A. Lambert. 1998. Taking account of peak areas when interpreting mixed DNA profiles. J. Forensic Sci. 43:62-69.

23.Evett, I.W., G. Jackson, and J.A. Lambert. 2000. More on the hierarchy of propositions: exploring the distinction between explanations and propositions. Sci. Justice 40:3-10.

24.Findlay, I., R. Frazier, A. Taylor, and A. Urquhart. 1997. Single-cell DNA fingerprinting for forensic applications. Nature 389:555-556.

25.Foreman, L.A. and I.W. Evett. 2001. Statistical analyses to support forensic interpretation for a new 10-locus STR profiling system. Int. J. Legal Med. 114:147-155.

26.Foreman, L.A., J.A. Lambert, and I.W. Evett. 1998. Regional genetic variation in Caucasians. Forensic Sci. Int. 95:27-37.

27.Frank, W.E. and B.E. Llewellyn. 1999. A time course study on STR profiles derived from human bone, muscle, and bone marrow. J. Forensic Sci. 44:778-782.

28.Fregeau, C.J., K.L. Bowen, J.H. Bowen, B.D. Gaudette, and R.M. Fourney. 1998. National casework and national DNA database: the royal Canadian mounted police perspective. Prog. Forensic Genet. 7:541-543.

29.Fregeau, C.J., O. Germain, and R.M. Fourney. 2000. Fingerprint enhancement revisited and the effects of blood enhancement chemicals on subsequent Profiler Plus fluorescent short tandem repeat DNA analysis of fresh and aged bloody fingerprints. J. Forensic Sci. 45:354-380.

30.Gill, P. and I.W. Evett. 1995. Population genetics of short tandem repeat (STR) loci. Genetica 96:69-87.

31.Gill, P., E. d'Aloja, J. Andersen, B. Dupuy, M. Jangblad, V. Johnsson, A.D. Kloosterman, A. Kratzer et al. 1997. Report of the European DNA profiling group (EDNAP): an investigation of the complex STR loci D21S11 and HUMFIBRA (FGA). Forensic Sci. Int. 18:25-33.

32.Gill, P., P.L. Ivanov, C. Kimpton, R. Piercy, N. Benson, G. Tully, I.W. Evett, E. Hagelberg et al. 1994. Identification of the remains of the Romanov family by DNA analysis. Nat. Genet. 6:130-135.

33.Gill, P., R. Sparkes, and J.S. Buckleton. 1998. Interpretation of simple mixtures when artifacts such as stutters are present-with special reference to multiplex STRs used by the Forensic Science Service. Forensic Sci. Int. 95:213-224.

34.Gill, P., R. Sparkes, L. Fereday, and D.J. Werrett. 2000. Report of the European Network of Forensic Science Institutes (ENSFI): formulation and testing of principles to evaluate STR multiplexes. Forensic Sci. Int. 108:129.

35.Gill, P., R. Sparkes, and C. Kimpton. 1997. Development of guidelines to designate alleles using an STR multiplex system. Forensic Sci. Int. 89:185-197.

36.Gill, P., A. Urquhart, E. Millican, N. OIdroyd, S. Watson, R. Sparkes, and C.P. Kimpton. 1996. A new method of STR interpretation using inferential logic-development of a criminal intelligence database. Int. J. Legal Med. 109:14-22.

37.Gill, P., R. Sparkes, R. Pinchin, T. Clayton, J. Whitaker, and J. Buckleton. 1998. Interpreting simple STR mixtures using allele peak areas. Forensic Sci. Int. 91:41-53.

38.Gill, P., J. Whitaker, C. Flaxman, N. Brown, and J. Buckleton. 2000. An investigation of 
the rigor of interpretation rules for STRs derived from less than $100 \mathrm{pg}$ of DNA. Forensic Sci. Int. 112:17-40.

39.Goodwin, W., A. Linacre, and P. Vanezis. 1999. The use of mitochondrial DNA and short tandem repeat typing in the identification of air crash victims. Electrophoresis 20:1707-1711.

40.Hochmeister, M.N., B. Budowle, J. Jung, U.V. Borer, C.T. Comey, and R. Dirnhofer. 1991. PCR-based typing of DNA extracted from cigarette butts. Int. J. Legal Med. 104:229-233.

41.Hoff-Olsen, P., B. Mevag, E. Staalstrom, B. Hovde, T. Egeland, and B. Olaisen. 1999. Extraction of DNA from decomposed human tissue. An evaluation of five extraction methods for short tandem repeat typing. Forensic Sci. Int. 105:171-183.

42.Hoyle, R. 1998. The FBI's national DNA database. Biotechnology 16:987.

43.Kimpton, C.P., P. Gill, E. d'Aloja, J.F. Andersen, W. Bar, S. Holgersson, S. Jacobsen V. Johnsson et al. 1995. Report on the second EDNAP collaborative STR exercise. European DNA Profiling Group. Forensic Sci. Int 71:137-152.

44.Kimpton, C.P., P. Gill., A. Walton, A. Urquhart, E.S. Millican, and M. Adams. 1993. Automated DNA profiling employing multiplex amplification of short tandem repeat loci. PCR Methods Appl. 3:13-22.

45.Ladd, C., M.S. Adamowicz, M.T. Bourke, C.A. Scherczinger, and H.C. Lee. 1999. A systematic analysis of secondary DNA transfer. J. Forensic Sci. 44:1270-1272.

46.Leriche, A., D. Vanek, H. Schmitter, U. Schleenbecker, J. Woller, P. Montagna, L. Garafano, and W. Sprangers. 1998. Final report of the Interpol Working Party on DNA profiling, p. 48-54. Proceedings from the 2nd European Symposium on Human Identification. Promega, Innsbruck, Austria.

47.Mills, K.A., D. Even, and J.C. Murray. 1992. Tetranucleotide repeat polymorphism at the human alpha fibrinogen locus (FGA). Hum. Mol. Genet. 1:779.

48.Mullis, K.B., F.A. Faloona, S. Scharf, R. Saiki, G. Horn, and H. Erlich. 1986. Specific enzymatic amplification of DNA in vitro: the polymerase chain reaction. Cold Spring Harb. Symp. Quant. Biol. 51:263-273.

49.Mullis, K.B. and F.A. Faloona. 1987. Specific synthesis of DNA in vitro via a polymerasecatalyzed chain reaction. Methods Enzymol. 155:335-350.

50.National Research Council. 1996. Statistical issues, p. 133-135. In The Evaluation of Forensic DNA Evidence. National Academy Press, Washington, D.C.

51. Olaisen, B., W. Bar, B. Brinkmann, B. Budowle, A. Carracedo, P. Gill, P. Lincoln, W.R. Mayr et al. 1998. DNA recommendations 1997 of the International Society for Forensic Genetics. Vox Sang. 74:61-63.

52. Olaisen, B., M. Stenersen, and B. Mevag. 1997. Identification by DNA analysis of the victims of the August 1996 Spitsbergen civil aircraft disaster. Nat. Genet. 15:402-405

53.Saiki, R.K., S. Scharf, F. Faloona, K.B. Mullis, G.T. Horn, H.A. Erlich, and N. Arnheim. 1985. Enzymatic amplification of $\beta$ - globin genomic sequences and restriction site analysis for diagnosis of sickle cell anemia. Science 230:1350-1354.

54.Schmerer, W.M., S. Hummel, and B. Herrmann. 2000. STR-genotyping of archaeological human bone: experimental design to improve reproducibility by optimization of DNA extraction. Anthropol. Anz. 58:29-35.

55.Schmerer, W.M., S. Hummel, and B. Herrmann. 1999. Optimized DNA extraction to improve reproducibility of short tandem repeat genotyping with highly degraded DNA as target. Electrophoresis 20:1712-1716.

56.Singer, V.L., L.J. Jones, S.T. Yue, and R.P. Haugland. 1997. Characterization of PicoGreen reagent and development of a fluorescence-based solution assay for doublestranded DNA quantitation. Anal. Biochem. 249:228-238

57.Sparkes, R., C. Kimpton, S. Gilbard, P. Carne, J. Andersen, N. Oldroyd, D. Thomas, A. Urquhart et al. 1996. The validation of a 7-locus multiplex STR test for use in forensic casework. (II) Mixtures, aging, degradation, and species studies. Int. J. Legal Med. 109:195-204

58.Sparkes, R., C. Kimpton, S. Watson, N. OIdroyd, T. Clayton, L. Barnett, J. Arnold, C. Thompson et al. 1996. The validation of a 7 locus multiplex STR test for use in forensic casework. (I) Mixtures, aging, degradation, and species studies. Int. J. Legal Med. 109:186-194.

59.Stockmarr, A. 1999. Likelihood ratios for evaluating DNA evidence when the suspect is found through a database search. Biometrics 55:671-677.

60.Strom, C.M. and S. Rechitsky. 1998. Use of nested PCR to identify charred human remains and minute amounts of blood. J. Forensic Sci. 43:696-700.

61.Sullivan, K.M., A. Mannucci, C.P. Kimpton, and P. Gill. 1994. A rapid and quantitative DNA sex test fluorescence-based PCR analysis of $\mathrm{X}-\mathrm{Y}$ homologous gene amelogenin. BioTechniques 15:636-641.

62.Sweet, D., J.A. Lorente, A. Valenzuela, M Lorente, and E. Villanueva. 1997. PCRbased DNA typing of saliva stains recovered from human skin. J. Forensic Sci. 42:447-451.

63.Taberlet, P., S. Griffin, B. Goossens, S. Questiau, V. Manceau, N. Escaravage, L.P. Waits, and J. Bouvet. 1996. Reliable genotyping of samples with very low DNA quantities using PCR. Nucleic Acids Res. 24:31893194

64. Van Hoofstat, D., D. Deforce, V. Brochez, I. De Pauw, K. Janssens, M. Mestdagh, R. Millecamps, E. Van Geldre et al. 1998. DNA typing of fingerprints and skin debris: sensitivity of capillary electrophoresis in forensic applications using multiplex PCR, p. 131-137. In Proceedings from the 2nd European Sym posium of Human Identification. Promega, Innsbruck, Austria.

65.Van Oorschot, R.A. and M.K. Jones. 1997. DNA fingerprints from fingerprints. Nature 387:767.

66. Van Renterghem, P.V., D. Leonard, and C. De Greef. 2000. Use of latent fingerprints as a source of DNA for genetic identification. Prog. Forensic Genet. 8:501-503.
67.Walsh, J.J. 1998. Canada's proposed forensic DNA evidence bank. Can. Soc. Forens. Sci. J. 31:113-125.

68.Walsh, P.S., J. Varanio, and R. Reynolds. 1992. A rapid chemiluminescent method for quantification of human DNA. Nucleic Acids Res. 20:5061-5065.

69.Walsh, P.S., N.J. Fildes, and R. Reynolds. 1996. Sequence analysis and characterization of stutter products at the tetranucleotide repeat locus vWA. Nucleic Acids Res. 24:28072812

70.Wiegand, P., T. Bajanowski, and B. Brinkmann. 1993. DNA typing of debris from fingernails. Int. J. Legal Med. 106:81-83.

71.Wiegand, P. and M. Kleiber. 1997. DNA typing of epithelial cells after strangulation. Int. J. Legal Med. 110:181-183.

72.Wiegand, P., K. Trubner, and M. Kleiber. 2000. STR typing of biological stains on strangulation tools. Prog. Forensic Genet. 8:508-510.

73.Weir, B.S. 1996. Genetic Data Analysis II. Sinauer Associates, Sunderland, MA.

74. Weir, B.S., C.M. Triggs, L. Starling, K.A.J. Stowell, and J. Buckleton. 1997. Interpreting DNA mixtures. J. Forensic Sci. 42:213-222.

75. Werrett, D.J. 1997. The National DNA Database. Forensic Sci. Int. 88:33-42.

76. Whitaker, J.P., T.M. Clayton, A.J. Urquhart, E.S. Millican, T.J. Downes, C.P. Kimpton, and P. Gill. 1995. Short tandem repeat typing of bodies from a mass disaster: high success rate and characteristic amplification patterns in highly degraded samples. BioTechniques 18:670-677.

Address correspondence to:

Dr. Peter Gill

Forensic Science Service

Trident Court

2960 Solihull Parkway

Birmingham B37 7YN, UK

e-mail:dnapgill@compuserve.com

For reprints of this or any other article, contact Reprints@BioTechniques.com 